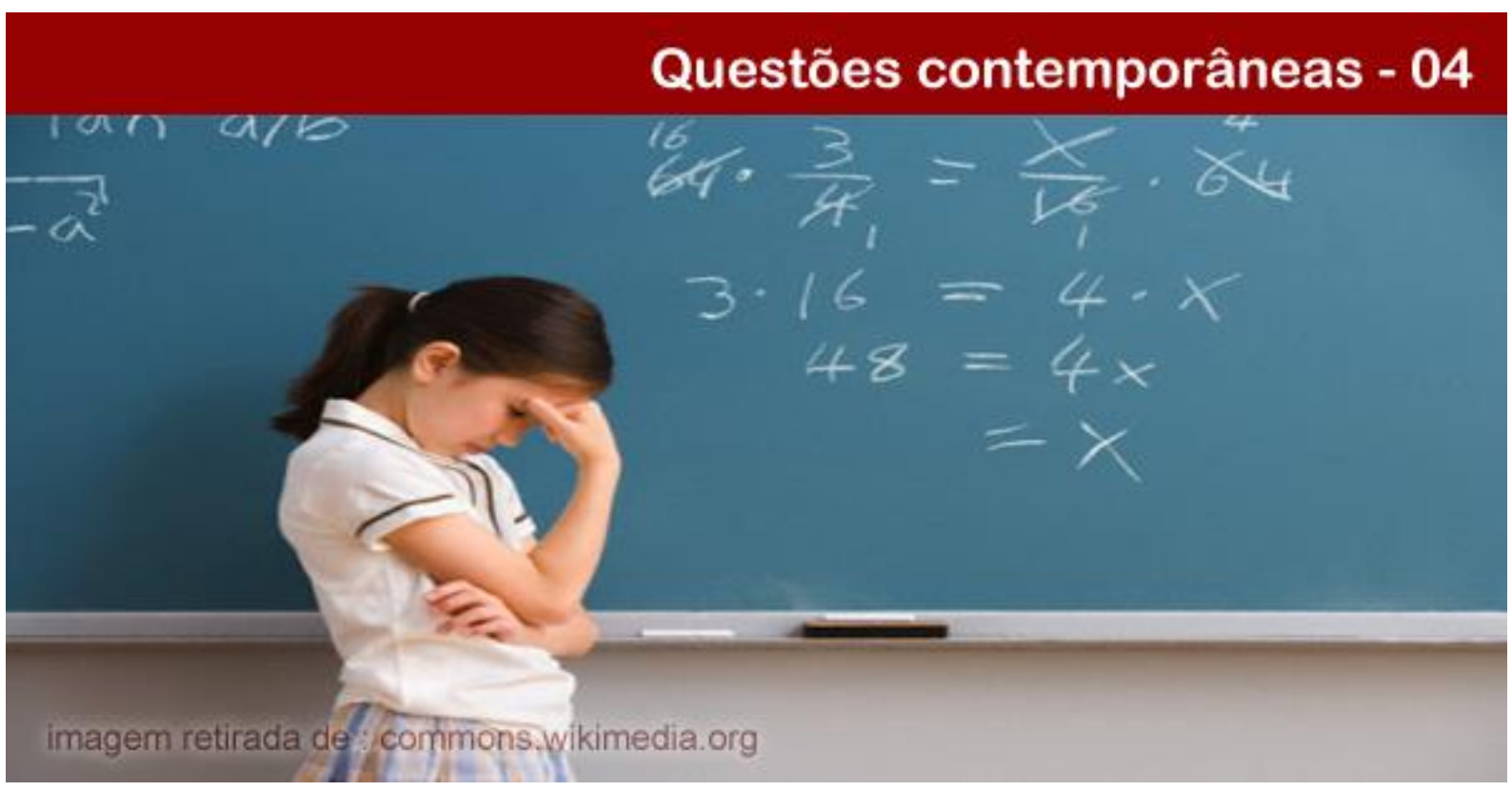

\title{
DE QUEM É A RESPONSABILIDADE PELO FRACASSO ESCOLAR?
}

\section{Simoni Jacomini de Souza}

Assistente Social Judicial no Tribunal de Justiça de Minas Gerais (TJMG.) e Professora Pedagoga na Prefeitura Municipal de Belo Horizonte. Mestra em Gestão Social, Educação e Desenvolvimento Local. E-mail: simoni.jacomini@gmail.com.

\section{Karina Barreto da Silva}

Professora Municipal de Belo Horizonte, eleita para a Direção de Instituição de Ensino triênio 2018-2020. Mestra em Gestão Social, Educação e Desenvolvimento Local. E-mail: kkpedagoga@yahoo.com.br.

Resumo: O presente estudo se constitui de uma reflexão sobre o percurso desenvolvido por professores e alunos de cinco turmas do $6^{\circ}$ ano do Ensino Fundamental de BH, no ano de 2017. A partir da discussão dos processos avaliativos e estratégias pedagógicas desenvolvidas pelos professores, buscou-se problematizar o trabalho escolar efetivamente realizado, tendo em vista a necessidade de identificar aspectos que incidem sobre a qualidade do processo educativo. Foi feita a análise dos parâmetros de aprovação e reprovação adotados pelos professores, bem como dos elementos que subsidiaram a decisão do Colegiado Escolar sobre o futuro escolar dos alunos selecionados, confrontando-os com as observações da equipe de coordenação pedagógica. Fundamentando-se nas contribuições de Bernard Charlot, Miguel Arroyo e Maria Helena Souza Patto sobre o fracasso escolar e nas discussões desenvolvidas por Cipriano Luckesi, Philippe Perrenoud e Edgar Morin acerca dos processos de avaliação escolar e da complexidade do processo educativo, espera-se despertar inquietações e explicitar os limites das diferenças ideológicas percebidas no trabalho educativo e contribuir para a construção de uma proposta de trabalho que explicite as diferenças e se comprometa profundamente com a reflexão crítica sobre a própria prática. Os resultados demonstram que a prática profissional ainda está calcada em vícios históricos e culturais que excluem os segmentos mais vulnerabilizados da sociedade e denunciam a irracionalidade de um sistema excludente, classificador, opressor e individualista, contrapondo-se ao discurso da universalização do ensino e do direito a uma educação pública de qualidade.

Palavras-chave: Avaliação escolar. Complexidade. Prática profissional.

\section{POLÊM!CA $\mid$ LABORE}

Polêmica - Revista Eletrônica da Uerj - Rua São Francisco Xavier, 524, $1^{\circ}$ andar bloco D, sl.1001 • Tels.: +55 21 2334-4088 / 4087 • http://www.e-publicacoes.uerj.br/index.php/polemica/index http://www.labore.uerj.br • laboreuerj@yahoo.com.br 


\title{
WHOSE IS RESPONSIBILITY FOR SCHOOL FAILURE?
}

\begin{abstract}
The present study consists of a reflection on the course developed by teachers and students of five groups of the 6th grade of BH Elementary School in the year 2017. From the discussion of the evaluation processes and pedagogical strategies developed by the teachers, to problematize the adequacy of the school work effectively carried out, considering the need to identify aspects that affect the quality of the educational process. The analysis of the approval and disapproval parameters adopted by the teachers, as well as the elements that subsidized the decision of the School Collegiate about the students' school future, were compared with the observations of the pedagogical coordination team. Based on the contributions of Bernard Charlot, Miguel Arroyo and Maria Helena Souza Patto on school failure and in the discussions developed by Cipriano Luckesi, Philippe Perrenoud and Edgar Morin on school evaluation processes and the complexity of the educational process, it is expected to arouse uneasiness and to explain the limits of the ideological differences perceived in the educational work and to contribute to the construction of a proposal of work that explains the differences and is deeply committed to the critical reflection on the practice itself. The results show that professional practice is still based on historical and cultural vices that exclude the most vulnerable segments of society and denounce the irrationality of an exclusionary, classifying, oppressive and individualistic system, in opposition to the discourse of universalization of education and law to a quality public education
\end{abstract}

Keywords: School evaluation. Complexity. Practice.

\section{Introdução}

O acesso universal à educação escolar obrigatória e gratuita, previsto pela Constituição Federal (BRASIL, 1988) e pela Lei de Diretrizes e Bases da Educação Nacional (LDBEN) (BRASIL, 1996), já é um grande progresso alcançado em nosso país, no tocante à oferta de ensino público à população brasileira. Este acesso, mesmo que, na prática, ainda seja deficitário, vem explicitar a importância de se colocar as discussões sobre educação pública na agenda política de governantes e agentes educacionais e ampliar o alcance dos necessários avanços construídos socialmente. Embora insuficiente, a existência de mecanismos legais que reconheçam a educação como direito social representa a legitimação de um direito até então destinado apenas às classes sociais mais abastadas.

No município de Belo Horizonte, desde 1995, o Ensino Fundamental está organizado em três ciclos de formação (infância, pré-adolescência e adolescência), com duração média de três anos, rompendo com a perspectiva milenar da seriação e com a cultura da reprovação nos anos iniciais de escolaridade. O $1^{\circ}$ ciclo compreende a faixa etária de 6 a 9 anos de idade (e corresponde ao $1^{\circ}, 2^{\circ}$ e $3^{\circ}$ ano na nomenclatura anterior), o $2^{\circ}$ ciclo corresponde à faixa etária de 9 a 12 anos de idade (equivalendo ao $4^{\circ}, 5^{\circ}$ e $6^{\circ}$ ano) e o $3^{\circ}$ ciclo compreende a faixa etária de 12 a 15 anos de idade (correspondendo ao $7^{\circ}, 8^{\circ}$ e $9^{\circ}$ ano). Esta inovação na organização do

\section{POLÊM!CA $\mid$ LABORE}

Polêmica - Revista Eletrônica da Uerj - Rua São Francisco Xavier, 524, $1^{\circ}$ andar bloco D, sl.1001 • Tels.: +55 21 2334-4088 / 4087 • http://www.e-publicacoes.uerj.br/index.php/polemica/index http://www.labore.uerj.br • laboreuerj@yahoo.com.br 
sistema educacional foi reconhecida e legitimada em 1996, com a aprovação da LDBEN, abrindo espaço para outras inovações no campo da educação pública.

Um aspecto que o presente estudo pretende enfatizar e provocar reflexões refere-se às concepções tradicionais de educação que ainda permeiam as práticas de atuais profissionais de educação e que, segundo hipótese das autoras e fundamentação teórica abordada, incidem negativamente na qualidade da educação pública.

A pesquisa se constitui, então, da observação participante e reflexão das autoras, que em 2017 exerceram a coordenação pedagógica ${ }^{1}$ em uma escola municipal de Belo Horizonte, sobre o percurso desenvolvido por professores e alunos do $6^{\circ}$ ano do Ensino Fundamental. Foi feita a análise dos parâmetros de aprovação e reprovação adotados pelos professores, bem como dos elementos que subsidiaram a decisão do Conselho Escolar sobre o futuro escolar dos alunos selecionados, confrontando-os com as observações da equipe de coordenação pedagógica, que acompanhou e orientou o trabalho pedagógico naquele ano.

A partir da análise desta coordenação sobre a prática desenvolvida pelos nove professores, bem como dos atendimentos individuais realizados aos alunos durante o ano, buscou-se problematizar o trabalho escolar efetivamente realizado, tendo em vista a necessidade de identificar aspectos que incidem sobre a qualidade do processo educativo praticado nas escolas.

Portanto, os dados foram obtidos a partir da observação de planejamentos, atividades, condutas docentes e processos avaliativos, registros no diário de classe, estratégias pedagógicas e comentários informais dos professores sobre os alunos. Também foram utilizados registros de atendimentos a alunos e famílias feitos pela coordenação pedagógica durante todo o ano de 2017. A pesquisa abrange, ainda, a revisão bibliográfica sobre o fracasso escolar, fundamentada nos aportes teóricos de Bernard Charlot, Miguel Arroyo e Maria Helena Souza Patto e nas contribuições de Cipriano Luckesi, Philippe Perrenoud e

\footnotetext{
1 A Prefeitura de Belo Horizonte não realiza concursos para Técnicos Superiores de Educação (TSE) ou Pedagogos desde 1987 e com o gradual decréscimo de servidores neste cargo, a coordenação pedagógica nas escolas passou a ser exercida por professores do quadro da própria escola, geralmente eleitos entre os seus pares, para assumir a função dos Técnicos Superiores de Ensino (TSE) e Pedagogos. Na referida escola, duas professoras assumiram a coordenação pedagógica após a última TSE aposentar-se.
}

\section{POLÊM!CA $\mid$ LABORE}

Polêmica - Revista Eletrônica da Uerj - Rua São Francisco Xavier, 524, $1^{\circ}$ andar bloco D, sl.1001 • Tels.: +55 21 2334-4088 / 4087 • http://www.e-publicacoes.uerj.br/index.php/polemica/index http://www.labore.uerj.br • laboreuerj@yahoo.com.br 
Edgar Morin acerca dos processos de avaliação escolar e da complexidade do processo educativo.

Como resultado, espera-se despertar inquietações e explicitar os limites das diferenças ideológicas percebidas no trabalho educativo, de forma a contribuir para a construção de uma proposta de educação que explicite as diferenças, ao mesmo tempo em que se comprometa profundamente com a reflexão crítica sobre a própria prática e para a superação do autoritarismo nas interações estabelecidas no ambiente escolar.

\section{Contextualização}

A escola pesquisada atende alunos do $1^{\circ}$ e $2^{\circ}$ ciclo do Ensino Fundamental, respectivamente nos turnos tarde e manhã, e localiza-se em um bairro popular de Belo Horizonte. Até o ano de 2016, os professores que atuavam na escola possuíam Licenciatura Plena em Normal Superior ou Pedagogia ou Graduação em área específica com habilitação em docência para os anos iniciais do Ensino Fundamental. Em consonância com a Portaria 317/2014 (BELO HORIZONTE, 2014), porém, a Secretaria Municipal de Educação (SMED) passou a incorporar, a partir daquele ano, os professores de disciplinas específicas, concursados para ministrarem aulas de Educação Física, Arte, Língua Estrangeira Moderna, Ciências Biológicas ou Biologia, Língua Portuguesa, História, Matemática e Geografia, e que atuavam em escolas de $3^{\circ}$ ciclo, para lecionarem, caso houvesse disponibilidade de profissionais no quadro de pessoal da SMED, no último ano do $2^{\circ}$ ciclo ( $6^{\circ}$ ano). Assim, em 2016, algumas escolas passaram a receber professores de disciplinas específicas e na escola em que foi realizada a presente pesquisa, no ano de 2017 , o quadro de professores do $6^{\circ}$ ano ficou assim constituído: dois professores de Matemática, uma professora de Língua Estrangeira (Inglês), uma professora de Geografia, um professor de Ciências, uma professora de Educação Física e três professoras generalistas ${ }^{2}$, que assumiram aulas de Língua Portuguesa e História.

\footnotetext{
${ }^{2}$ A expressão indica professores que apresentam formação em cursos de Pedagogia ou que, mesmo com licenciatura em determinada área do conhecimento (Letras, História, etc.), prestaram concurso para ministrar aulas nos anos iniciais do Ensino Fundamental, de conteúdos independentes de sua formação acadêmica.
}

\section{POLÊM!CA $\mid$ LABORE}

Polêmica - Revista Eletrônica da Uerj - Rua São Francisco Xavier, 524, $1^{\circ}$ andar bloco D, sl.1001 • Tels.: +55 21 2334-4088 / 4087 • http://www.e-publicacoes.uerj.br/index.php/polemica/index http://www.labore.uerj.br • laboreuerj@yahoo.com.br 
A inclusão de docentes de disciplinas específicas no quadro da escola provocou uma reestruturação na maneira como as aulas eram distribuídas entre os professores e nas formas de interação dos professores com os alunos. A especialização do saber, por sua vez, impôs-se de forma contundente, tendo em vista a aparente insuficiência de conhecimento científico que vários professores que atuam no $1^{\circ}$ e $2^{\circ}$ ciclos apresentam - posto que a formação em Pedagogia privilegia a didática e a metodologia, em detrimento dos conteúdos específicos das disciplinas.

Este fato conduz à reflexão sobre a importância da formação de professores como elemento para a qualidade do ensino. Mais que conteúdos específicos, a educação na modernidade desafia a formação do aluno pensante, autônomo, capaz de aprender a aprender. Saviani (2009) observa que a emergência da formação de professores surgiu junto com as escolas, no século XI, embora somente a partir do ano de 1890 fossem criadas as chamadas Escolas Normais, “de nível médio, para formar professores primários atribuindo-se ao nível superior a tarefa de formar os professores secundários" (SAVIANI, 2009, p. 148).

Para o autor (2009), a formação de professores se fundamenta sobre dois modelos distintos: o dos conteúdos culturais-cognitivos, que privilegia a cultura geral e o domínio dos conteúdos de determinada área de conhecimento; e o pedagógico-didático, que visa ao efetivo preparo do professor no campo que nomeia o modelo. Segundo Saviani, é necessário articular ambos os modelos em torno da formação do professor, pois ambos são aspectos indissociáveis do ato docente.

Conforme observam Pachane e Domiciano (2013), ainda são pouco expressivas as produções acadêmicas sobre formação de professores que lecionam disciplinas específicas na educação básica. Para os autores, é importante conceber a formação dos professores, articulando tanto a dimensão da teoria como da prática, sugerindo "intercâmbios entre as áreas das especificidades e pedagógicas, no intuito de ampliar as discussões sobre como se dá a formação de formadores no país" (2013, p. 174). Embora os professores universitários brasileiros apresentem uma tendência a minimizar a importância do aspecto pedagógico na formação dos professores, como observa Saviani (2009), ao denunciar que "não deixa de estar presente também no ethos dos professores universitários brasileiros uma certa depreciação do

\section{POLÊM!CA $\mid$ LABORE}

Polêmica - Revista Eletrônica da Uerj - Rua São Francisco Xavier, 524, $1^{\circ}$ andar bloco D, sl.1001 • Tels.: +55 21 2334-4088 / 4087 • http://www.e-publicacoes.uerj.br/index.php/polemica/index http://www.labore.uerj.br • laboreuerj@yahoo.com.br 
aspecto pedagógico", "as desigualdades extremas obrigam a uma maior sensibilidade para o aspecto educativo" (2009, p. 150).

\section{O fracasso escolar na perspectiva de Bernard Charlot}

As questões que serviram de motivação para as investigações de Bernard Charlot sobre a relação com o saber no meio educacional permanecem, intrigam e parecem não ter respostas dentro das instituições escolares, principalmente naquelas que se encontram em áreas de periferia urbana e nas quais a maior parte dos alunos tende a não alcançar êxito em sua trajetória escolar. De acordo com Charlot, “o 'fracasso escolar' não existe; o que existe são alunos fracassados, situações de fracasso, histórias escolares que terminam mal” (2000, p. 16). O fracasso escolar, segundo o autor, não pode, portanto, ser tomado como objeto de pesquisa. Deve-se, por conseguinte, analisar os alunos, o conjunto de fenômenos observados e as condições que compõem o quadro de insucesso dos processos de ensino aprendizagem. Esses são fatores que merecem atenção e devem ser investigados.

Outra ideia que permeia o âmbito educacional, e que o autor desconstrói, é sobre a origem social do fracasso escolar. Nas escolas, é muito comum os educadores atribuírem à posição social das famílias e ao contexto sociocultural o fracasso escolar das crianças. Neste contexto, a culpa do fracasso escolar é totalmente vinculada ao aluno e definida por suas condições sociais e carência cultural, uma perspectiva determinista e tendenciosa, que atribui à realidade um caráter imutável e desconsidera a possibilidade pragmática de encontrar soluções para os problemas, predestinando o aluno ao insucesso.

A reprodução da teoria sociológica fundamentada no conceito de habitus ${ }^{3}$ explica o fracasso escolar por meio da diferença da posição que o aluno ocupa no espaço social e escolar. Essa posição é determinada pela posição social dos pais, conforme explica Charlot, que faz com que as crianças oriundas de famílias desfavorecidas estejam mais suscetíveis ao

\footnotetext{
${ }^{3} \mathrm{O}$ conceito de habitus é definido pelo sociólogo Pierre Bourdieu como sendo "um sistema de disposições duráveis e transponíveis que, integrando todas as experiências passadas, funciona em cada momento como uma matriz de percepções, apreciações e ações - e torna possível a realização de tarefas infinitamente diferenciadas, graças às transferências analógicas de esquemas, que permitem resolver os problemas da mesma forma, e às correções incessantes dos resultados obtidos, dialeticamente produzidas por esses resultados.” (ORTIZ, 1983, p. $65)$.
}

\section{POLÊM!CA $\mid$ LABORE}

Polêmica - Revista Eletrônica da Uerj - Rua São Francisco Xavier, 524, $1^{\circ}$ andar bloco D, sl.1001 • Tels.: +55 21 2334-4088 / 4087 • http://www.e-publicacoes.uerj.br/index.php/polemica/index http://www.labore.uerj.br • laboreuerj@yahoo.com.br 
fracasso devido à sua origem de classe. Outra interpretação realizada sob a ótica da teoria das sociologias da reprodução para denunciar o fracasso escolar é pensar a diferença como deficiência sociocultural. Segundo Charlot, a "teoria da deficiência sociocultural pratica uma leitura 'negativa' da realidade social, que ela interpreta em termos de falta" (CHARLOT, 2000, p. 29). Ainda de acordo com o autor, a partir desta perspectiva, o aluno passa a ser pensado equivocadamente como um objeto, assim como o que lhe falta, suas lacunas e carências. Ou seja, ao considerar a origem social como principal fator responsável pelo fracasso escolar, os professores adotam uma percepção predeterminista da realidade, considerando-a como imutável, pré-concebida e restrita a partir de suas ideias e julgamentos, o que desmotiva suas proposições para melhoria da situação de aprendizagem dos alunos.

Charlot (2000) acredita que há uma correlação entre o fracasso escolar e as desigualdades sociais, mas não admite que esta explicação seja suficiente para justificar o fracasso de muitos alunos, fenômeno que envolve uma complexidade de situações. $\mathrm{O}$ autor também não atribui exclusivamente à família a responsabilidade pelo fracasso escolar dos alunos. Para ele, esta é uma construção teórica advinda da experiência dos docentes e de uma interpretação subjetiva realizada de acordo com interesses ideológicos que proporcionam benefícios aos próprios professores, preservando-os de críticas. Os adeptos de tal ponto de vista estão convencidos de que o fracasso escolar incide sobre o aluno desprovido de competências necessárias ao ambiente escolar e que a causa para tal teria origem no âmbito familiar, responsável pela produção das deficiências e, consequentemente, pelo fracasso escolar.

A culpabilização dos alunos e do seu contexto social pelo fracasso acaba por cristalizar as deficiências, que são configuradas como uma realidade permanente, eximindo a escola e seus atores do dever de problematizar suas práticas e buscar soluções junto à comunidade para modificação das circunstâncias ligadas às dificuldades encontradas (SENICATO; OMETO, 2014). Para que haja uma mudança nessa situação, Charlot (2000) propõe a prática epistemológica e metodológica de uma leitura "positiva" dos alunos, segundo a qual o educador deve ater-se ao que os alunos conseguem realizar, deixando de ressaltar somente suas falhas e carências.

\section{POLÊM!CA $\mid$ LABORE}

Polêmica - Revista Eletrônica da Uerj - Rua São Francisco Xavier, 524, $1^{\circ}$ andar bloco D, sl.1001 • Tels.: +55 21 2334-4088 / 4087 • http://www.e-publicacoes.uerj.br/index.php/polemica/index http://www.labore.uerj.br • laboreuerj@yahoo.com.br 


\section{A cultura do fracasso escolar: uma investigação necessária}

Para Miguel Arroyo (1992), a cultura do fracasso escolar cristaliza as diferenças e segrega grupos culturalmente excluídos. Considerando a história da educação brasileira, esta cultura influencia ainda hoje as práticas docentes e os discursos, tanto de professores, profissionais da área e gestores, como de alunos e suas famílias. A própria pedagogia e a didática são influenciadas por esta cultura, tornando os currículos, as metodologias e as interações sociais estabelecidas na escola, contaminadas por uma concepção elitista, preconceituosa, seletiva e excludente de educação.

Arroyo defende a estruturação dos níveis de ensino em ciclos identitários de idade, conhecimentos, experiências, valores, integração e formação. A cultura do fracasso é combatida pela permanência no ciclo, de um ano a outro, de forma a garantir ao aluno a experiência formadora com seus pares de idade, evitando o critério de reprovação por incapacidade. Se, ao final de um ciclo, o aluno não obtiver resultados satisfatórios, será discutida sua permanência no ciclo por mais um ano, no sentido de garantir um atendimento individualizado às defasagens apresentadas. Esta concepção, para o autor, influencia a decisão sobre o que ensinar, formas de avaliar, reprovar ou aprovar. Arroyo se alicerça na pedagogia freiriana, concordando com a proposição de que da mesma forma que a palavra geradora não é um dado ou doação do educador, "não é também lícito pretender apresentar a forma atual de democracia como se fora uma dádiva das elites, como se fora a única democracia possível e à qual o povo teria de acomodar-se (FREIRE, 2015, p. 12). Neste sentido, ele propõe uma concepção radicalmente democrática de educação básica, em que a reprovação seja tratada com seriedade, justificando-se apenas mediante uma proposta baseada no profundo conhecimento do aluno, de suas dificuldades, avanços, potencialidades e da escolha criteriosa de metodologias, conteúdos e mecanismos de aprovação futura.

Considerando o processo educativo como um trabalho de parceria entre professor e aluno, é fundamental que as interações aconteçam em um nível cooperativo, não no sentido de impor uma ou outra vontade, mas no investimento recíproco em um processo colaborativo, de construção coletiva de conhecimentos válidos e significativos. Por isso, o papel do professor é promover a liberdade e, ao mesmo tempo, a autoridade, negociando os limites e respeitando

\section{POLÊM!CA $\mid$ LABORE}

Polêmica - Revista Eletrônica da Uerj - Rua São Francisco Xavier, 524, $1^{\circ}$ andar bloco D, sl.1001 • Tels.: +55 21 2334-4088 / 4087 • http://www.e-publicacoes.uerj.br/index.php/polemica/index http://www.labore.uerj.br • laboreuerj@yahoo.com.br 
os saberes dos educandos. Para Paulo Freire, "é decidindo que se aprende a decidir" (1997, p. 119). O aluno só aprenderá a ser ele mesmo se tiver a liberdade de ser quem é, mediada pela responsabilidade e pela assunção das consequências de suas escolhas. O professor é papel fundamental neste processo, pois pode possibilitar conduzir a tomada de decisões de forma ética e responsável.

Ao reconhecer e valorizar os saberes dos alunos, o professor legitima e valoriza a diversidade, a dúvida, a incerteza e a insuficiência do conhecimento, abrindo espaço para interações mais horizontalizadas. Diante disso, o processo avaliativo deixa de ser um processo de aferição do que não se sabe, mas passa a se constituir como instrumento de análise crítica da prática, de confrontação dos limites do conhecimento, da autonomia para a construção dos saberes. Segundo Maria Helena Souza Patto (1999), a aprovação ou reprovação depende muito mais de condições aleatórias que não se relacionam com as capacidades intelectuais e cognitivas dos alunos. Na realidade é uma decisão arbitrária, que pode explicar, inclusive, o fracasso escolar das populações mais pobres.

A prática da avaliação educacional escolar, segundo Luckesi (2014), está a serviço de um entendimento teórico conservador da sociedade e da educação, e não a serviço da transformação social - o que justifica a hipervalorização dos exames como instrumentos de avaliação largamente utilizados nas escolas brasileiras. Em consonância, Perrenoud (2015) explica que o conhecimento escolar não deve se basear na mera transmissão de conceitos. Ele precisa considerar que "ninguém pode realizar uma atividade de reorganização da rede de conceitos e de representações do mundo no lugar do sujeito aprendente" (PERRENOUD, 2015, p. 78). O professor que compreende esta premissa sabe que mais que conteúdos, é preciso criar situações de aprendizagem, reconhecendo que o aluno irá aprender a partir de suas características singulares e dos sentidos que o objeto de conhecimento representa em sua vida pessoal.

Entende-se que a educação precisa se vincular à tentativa de desvelar a realidade, denunciando as contradições e atuando sobre elas, fomentando o desenvolvimento de uma consciência contraideológica. De acordo com Edgar Morin (2007), há problemas centrais em todas as sociedades e culturas que a educação deste século deve abordar, e que se constituem

\section{POLÊM!CA $\mid$ LABORE}

Polêmica - Revista Eletrônica da Uerj - Rua São Francisco Xavier, 524, $1^{\circ}$ andar bloco D, sl.1001 • Tels.: +55 21 2334-4088 / 4087 • http://www.e-publicacoes.uerj.br/index.php/polemica/index http://www.labore.uerj.br • laboreuerj@yahoo.com.br 
como eixos para uma educação integral. Para este autor, todos "vivem os mesmos problemas fundamentais de vida e de morte e estão unidos na mesma comunidade de destino planetário." (2007, p. 76). O autor amplia a ideia de cultura, pensando a educação como instrumento para aprender a viver no planeta Terra, desenvolvendo a consciência antropológica, ecológica, cívica, terrena e espiritual da condição humana.

Ao defender a importância de se desenvolver o pensamento complexo e combater a fragmentação do conhecimento, o autor sinaliza para a necessidade de uma reforma do ensino, pois o compartimento dos saberes em disciplinas não favorece a contextualização. Sem perceber o todo, o conhecimento torna-se incapaz de pensar a multidimensionalidade dos problemas atuais, para o enfrentamento dos quais deve contribuir. A hiperespecialização, ao fragmentar o global em parcelas, impede “apreender 'o que é tecido junto', isto é, o complexo, segundo o sentido original do termo" (MORIN, 2003, p. 14).

Aí reside um dos desafios do pensamento complexo na educação. O sistema organizado em disciplinas desarticuladas entre si necessita que os saberes sejam religados, o que conduz à ideia da transdisciplinaridade. Morin entende que a escola tem o papel não de tornar as cabeças "bem cheias", mas de favorecer que as cabeças se tornem "bem feitas", no sentido de que, mais que acumular saberes, é preciso aprender a se posicionar no mundo, mobilizar-se para tratar os problemas e atribuir sentido aos conhecimentos que desenvolver. Embora os desafios sejam apresentados separadamente, eles devem ser vistos como interdependentes.

\section{Afinal, o que determina aprovar ou reprovar um aluno?}

$\mathrm{Na}$ escola pesquisada, o ano letivo foi dividido em três etapas, sendo que no início de cada uma delas, os professores deveriam apresentar à coordenação pedagógica o planejamento referente aos conteúdos que seriam trabalhados em sua disciplina, bem como formas de avaliação e pontuação atribuída a cada atividade. Ao final do ano, os alunos que não obtiveram no mínimo sessenta por cento (60\%) de aproveitamento participaram da Oportunidade Especial de Recuperação (OER), no valor total de em (100) pontos, ocasião em que deveriam apresentar trabalhos e teriam oportunidade para realizar uma nova avaliação. A

\section{POLÊM!CA $\mid$ LABORE}

Polêmica - Revista Eletrônica da Uerj - Rua São Francisco Xavier, 524, $1^{\circ}$ andar bloco D, sl.1001 • Tels.: +55 21 2334-4088/4087 • http://www.e-publicacoes.uerj.br/index.php/polemica/index http://www.labore.uerj.br • laboreuerj@yahoo.com.br 
rede municipal de Belo Horizonte utiliza como critério para reprovação a insuficiência em três ou mais disciplinas, de forma não hierarquizada.

A Coordenação Pedagógica mantinha registros individuais dos alunos, que continham informações sobre seu comportamento em sala, interações com os colegas e professores, apresentação de trabalhos, intervenções realizadas com o próprio aluno ou com seus familiares, questões de saúde, dentre outras. Estes registros eram realizados, na maioria das vezes, nas ocasiões em que o aluno era encaminhado à sala da Coordenação pelos professores. A Coordenação também se responsabilizava pela análise dos planejamentos docentes, bem como pelo acompanhamento do trabalho pedagógico desenvolvido pelos professores, com vistas a alcançar os objetivos previstos para cada turma.

Estes registros subsidiaram as análises que são apresentadas neste trabalho, haja vista que foi observada inconsistência entre os registros oficiais dos professores em relação ao perfil das turmas, planejamento dos conteúdos a serem trabalhados, formas avaliativas e estratégias assumidas pelos docentes na condução das aulas. Naquele ano, a coordenação pedagógica encontrou dificuldades em sensibilizar os professores para a importância dos registros, para a entrega em tempo hábil do planejamento e das notas de alunos e, em alguns casos, observou-se que os professores não respeitavam os prazos previstos ou entregavam o que lhes era solicitado sem muita preocupação com a veracidade das informações. Frequentemente os professores demandavam à coordenação a tarefa de intervir junto aos alunos por problemas de comportamento, indisciplina, ausência de material, não realização de tarefas extraclasse, dentre outros fatores que, em tese, seriam de responsabilidade do professor. Estes aspectos foram abordados nos diferentes momentos em que a coordenação pedagógica se reunia com grupos de professores, mas a situação perdurou até o final do ano sem alterações.

Feitas estas considerações, será analisado um processo decisório do Conselho de Classe realizado entre professores do $6^{\circ}$ ano, em relação à aprovação e reprovação de três alunos que, durante o ano de 2017, apresentaram rendimento inferior a sessenta por cento (60\%) do total de cem (100) pontos distribuídos. Os nomes dos alunos serão omitidos, e utilizadas as letras A, B e C para identificá-los. A escolha dos três alunos foi baseada em

\section{POLÊM!CA $\mid$ LABORE}

Polêmica - Revista Eletrônica da Uerj - Rua São Francisco Xavier, 524, $1^{\circ}$ andar bloco D, sl.1001 • Tels.: +55 21 2334-4088 / 4087 • http://www.e-publicacoes.uerj.br/index.php/polemica/index http://www.labore.uerj.br • laboreuerj@yahoo.com.br 
semelhanças em relação à pontuação anual obtida, bem como às anotações referentes ao comprometimento e responsabilidade demonstrados em relação aos estudos, participação da família no processo educativo e habilidades e capacidades cognitivas apresentadas. Os três alunos apresentaram, também, graus variados de comportamentos considerados indisciplinados pelos professores, que registraram em um Diário de Bordo as ocasiões em que deixaram de cumprir alguma tarefa escolar, perturbaram a aula, não apresentaram o material necessário ou conversaram em demasia. A despeito destas semelhanças, a decisão pela aprovação foi diferente para cada caso, o que será objeto de estudo e comparação nesta análise.

Como ao término das três etapas do ano letivo, os resultados apresentados pelos três alunos foram insuficientes para aprovação, ou seja, os alunos obtiveram menos de 60 pontos em três ou mais disciplinas, eles se submeteram à Oportunidade Especial de Recuperação (OER), como última e decisiva etapa para aprovação.

Após o período da OER, os alunos não apresentaram avanços significativos, tendo sido considerada a maior nota obtida em quaisquer dos dois períodos avaliados (notas anuais ou OER). O quadro abaixo demonstra a pontuação obtida pelos alunos nas duas oportunidades:

Quadro - 1: Notas obtidas durante o ano pelos alunos A, B e C após a OER

\begin{tabular}{|l|c|c|c|c|c|c|c|c|c|c|c|c|}
\hline Disciplina & \multicolumn{2}{|c|}{ Ciências } & \multicolumn{2}{|c|}{ Geografia } & \multicolumn{2}{c|}{ História } & \multicolumn{2}{|c|}{ L. Port. } & \multicolumn{2}{c|}{ Matemática } & \multicolumn{2}{c|}{ Inglês } \\
\hline Notas: & Anual & OER & Anual & OER & Anual & OER & Anual & OER & Anual & OER & Anual & OER \\
\hline Aluno A & 42 & 13,5 & 30 & 6 & 30 & 30 & 32 & 60 & 21 & X & 16 & 50 \\
\hline Aluno B & 47 & 6 & 59 & 9 & 30 & 40 & 52 & 60 & 14 & X & 37 & 15 \\
\hline Aluno C & 57 & 9 & 39 & 5 & $\mathbf{6 0}$ & $\mathbf{6 0}$ & 46 & $\mathbf{6 0}$ & 52 & 41 & 58 & 20 \\
\hline
\end{tabular}

Fonte: Registros nos diários de classe das turmas de $6^{\circ}$ ano.

Como os três alunos não obtiveram nota mínima necessária para aprovação mesmo após a OER, coube ao Conselho de Classe a decisão sobre aprovar ou não cada um. O Conselho de Classe é a instância legítima na escola para discutir o processo de avaliação, referendando ou alterando os resultados obtidos pelos alunos, e é composto pelos professores, coordenação e, quando necessário, direção da escola.

\section{POLÊM!CA $\mid$ LABORE}

Polêmica - Revista Eletrônica da Uerj - Rua São Francisco Xavier, 524, $1^{\circ}$ andar bloco D, sl.1001 • Tels.: +55 21 2334-4088/4087 • http://www.e-publicacoes.uerj.br/index.php/polemica/index http://www.labore.uerj.br • laboreuerj@yahoo.com.br 
Nota-se que as notas da OER apresentaram-se, em sua maioria, menores que as notas anuais, o que demonstra sua insuficiência para recuperar conhecimentos não apreendidos. Das seis disciplinas, o aluno $\mathrm{C}$ foi o único que conseguiu aprovação em duas disciplinas, enquanto os alunos A e B mantiveram desempenho insuficiente em todas elas. Em Matemática, os alunos A e B não realizaram trabalhos ou provas referentes à OER, tendo mantido as notas insuficientes obtidas durante o ano. Estranhamente, no entanto, a decisão do Conselho de Classe foi aprovar os alunos A e B e reprovar o aluno C.

$\mathrm{Na}$ tentativa de compreender o que levou os professores a aprovarem os alunos A e B e reprovarem o aluno $\mathrm{C}$, verificou-se que a decisão pela aprovação ou reprovação foi tomada pelos professores durante o Conselho de Classe, após ponderarem os parâmetros que utilizaram para a decisão, destacando, principalmente, aspectos comportamentais dos alunos, independentemente dos aspectos cognitivos. Nesta ocasião, as coordenadoras questionaram tais parâmetros, uma vez que a decisão por reprovação deveria se basear em critérios objetivos referentes à aprendizagem. Além disto, a coordenação reiterou o papel do Conselho de Classe, que deveria discutir o processo educativo sob uma perspectiva formativa, investigativa, processual e contínua, não apenas como instância legítima para alterar notas a bel prazer.

As justificativas apresentadas, no entanto, demonstraram a intenção dos docentes punirem o aluno que mostrou-se desafiador durante todo o ano, embora tenha apresentado desempenho melhor e menos registros de indisciplina que os colegas. Um professor argumentou que a aprovação seria "um desaforo", tendo em vista que o aluno C não realizou as tarefas referentes ao período de OER, embora sua pontuação tenha sido relativamente satisfatória durante o ano. Mesmo sendo avaliado como capaz em dados conteúdos, a falta de compromisso com a apresentação de trabalhos foi fundamental para a reprovação do aluno C. Este mesmo critério, porém, foi desconsiderado em relação aos alunos A e B, que também não realizaram as atividades de OER em matemática. Em vez de focar o trabalho ao atendimento individualizado das defasagens destes alunos, como defendido por Arroyo (1992), os docentes utilizaram-se de critérios pessoais, conduta corporativa e culpabilização do aluno pela sua reprovação e insucesso escolar.

\section{POLÊM!CA $\mid$ LABORE.}

Polêmica - Revista Eletrônica da Uerj - Rua São Francisco Xavier, $524,1^{\circ}$ andar bloco D, sl.1001 • Tels.: +55 21 2334-4088 / 4087 • http://www.e-publicacoes.uerj.br/index.php/polemica/index http://www.labore.uerj.br • laboreuerj@yahoo.com.br 
Alguns destes argumentos apresentados pelos professores corroboram o que Jacomini (2010) avalia como resultado oposto ao esperado no que se refere à ameaça da reprovação. Enquanto alguns professores defendem que a possibilidade de reprovação pode alterar a disposição do aluno para os estudos, a autora argumenta que o efeito pode ser o de desestimular e minar a autoconfiança do aluno. Neste contexto, a escola reproduz o autoritarismo, a arbitrariedade, a ausência de critérios conceituais consistentes, o verticalismo e o exercício abusivo do poder, que compõem a tradição política, social e cultural brasileira.

Verificou-se, ainda, que, durante o Conselho de Classe, os professores que defenderam com mais veemência a reprovação do aluno $\mathrm{C}$ não apresentaram o planejamento de todas as etapas, assim como não lançaram as notas de recuperação da $3^{\text {a }}$ etapa em tempo hábil, de forma a facilitar às famílias acompanharem o desempenho de seus filhos. A ausência de registros e argumentos consistentes e de estratégias docentes durante o ano para coibir situações que prejudicavam a aprendizagem, a falta de acompanhamento familiar no processo escolar de seus filhos e o corporativismo demonstrado pelos professores demonstram que a aprovação ou reprovação destes alunos foi baseada em razões subjetivas.

A questão que se coloca, neste caso, é: por que o aluno C não foi avaliado da mesma forma que seus colegas, principalmente tendo em vista que suas notas anuais superaram as notas dos alunos A e B? Este fato demonstra que, ainda que o aluno $\mathrm{C}$ tenha se empenhado mais durante todo o ano, o Conselho de Classe foi a instância determinante para sua reprovação. Além disto, na maioria das disciplinas seu desempenho foi próximo do mínimo necessário, mas, ainda assim, não conseguiu que o Conselho de Classe deliberasse por sua aptidão para a continuidade dos estudos no $3^{\circ}$ ciclo.

Tais constatações demonstram que os parâmetros utilizados pelos professores para reprovar o aluno $\mathrm{C}$ ou aprovar os alunos A e B não são defensáveis, do ponto de vista ético ou pedagógico. A partir da leitura dos registros de atendimentos individuais realizados pela Coordenação durante todo o ano, verificou-se que os alunos A e B demonstraram comportamentos que prejudicavam a qualidade do clima escolar, envolvendo-se frequentemente em conflitos com colegas e descompromisso com os estudos. Estes alunos eram encaminhados à Coordenação com bastante frequência, tendo sido alvo de intervenções

\section{POLÊM!CA $\mid$ LABORE}

Polêmica - Revista Eletrônica da Uerj - Rua São Francisco Xavier, 524, $1^{\circ}$ andar bloco D, sl.1001 • Tels.: +55 21 2334-4088 / 4087 • http://www.e-publicacoes.uerj.br/index.php/polemica/index http://www.labore.uerj.br • laboreuerj@yahoo.com.br 
tanto junto aos alunos como às suas famílias. O aluno $\mathrm{C}$, por sua vez, embora não apresentasse problemas com os pares, mostrou-se pouco permeável às intervenções dos professores, demonstrando ignorar e mesmo afrontar suas recomendações. Associado a isto, um episódio ocorrido na última semana letiva chama bastante atenção: o aluno $\mathrm{C}$ foi repreendido no primeiro dia previsto para realização das provas da OER por se atrasar para entrar na sala, fato já registrado anteriormente no Diário de Bordo, com frequência durante o ano, e não mereceu qualquer intervenção dos professores, a não ser impedi-lo de assistir a aula que já iniciara. Além disto, ao ser repreendido pelo atraso, o aluno $\mathrm{C}$ portou-se de forma arrogante, desafiando a autoridade dos professores. Isto motivou a equipe de professores a exigir a presença do responsável no mesmo dia e informar que a aprovação do aluno, diante de tal conduta, estaria seriamente comprometida, ainda que o processo final de avaliação não estivesse concluído. Neste dia, somente após intervenção da Direção da escola os professores concordaram que o aluno $\mathrm{C}$ realizasse as provas de OER, previstas para aquela semana.

A argumentação apresentada pelos docentes para aprovar os alunos com problemas mais graves de disciplina foi exatamente a dificuldade que os professores teriam para controlar a disciplina da turma no ano seguinte, quando estes mesmos alunos retornassem à escola. Ou seja, paradoxalmente, os alunos A e B foram aprovados por terem chegado ao limite do mau comportamento; seguindo ao $3^{\circ}$ ciclo, seriam conduzidos a uma outra escola. Em relação ao aluno $\mathrm{C}$, sua reprovação serviria de modelo a não ser seguido pelos alunos dos anos anteriores, demonstrando que a reprovação por mau comportamento, desde que não seja extremo, constitui-se uma espécie de castigo pela desobediência. Esta situação conduz a uma conclusão perturbadora: os professores demonstram que, em alguns casos, a reprovação, por si só, pode ser benéfica apenas a alguns alunos, ainda que não haja nenhuma estratégia pensada e desenvolvida para contornar as defasagens de aprendizagem.

\section{Considerações finais}

$\mathrm{O}$ aluno $\mathrm{C}$ teve notório prejuízo, tanto no prazo para execução das atividades avaliativas, como no rigor com que foi avaliado pelos professores, que concordaram em aplicar as provas finais somente após intervenção da Direção da escola. Além disto, sua

\section{POLÊM!CA $\mid$ LABORE}

Polêmica - Revista Eletrônica da Uerj - Rua São Francisco Xavier, 524, $1^{\circ}$ andar bloco D, sl.1001 • Tels.: +55 21 2334-4088 / 4087 • http://www.e-publicacoes.uerj.br/index.php/polemica/index http://www.labore.uerj.br • laboreuerj@yahoo.com.br 
autoconfiança foi abalada, uma vez que os professores indicaram sua reprovação antes mesmo de concluir a etapa de OER. A reprovação, pelo que fica demonstrado, deveu-se a este ato de insubordinação do aluno e de exercício arbitrário do poder professoral, contrariando as orientações da Secretaria Municipal de Educação, de que "o combate à repetência/retenção não significa um compromisso menor com o processo de ensino-aprendizagem” [...], uma vez que "o desempenho do estudante deve ser avaliado desde o início do ano, em todos os componentes curriculares em relação a ele mesmo" (PBH, 2016, p. 46). Evidentemente, o caso exemplifica a inobservância de vários aspectos da avaliação e do processo de recuperação.

Tal constatação sinaliza para a arbitrariedade do processo avaliativo e pela falta de clareza nos critérios utilizados pelos professores para avaliar seus alunos. Fatores subjetivos interferiram significativamente no processo, e ainda que os professores de Língua Estrangeira e Língua Portuguesa tenham ponderado que a reprovação não seria a melhor alternativa, os demais professores insistiram em apelar para a soberania do Conselho de Classe, numa demonstração da fragilidade do senso de justiça em relação à imposição do corporativismo.

Não se trata de questionar a reprovação de um aluno, mas discutir: o que fez, então, com que outros alunos fossem aprovados, mesmo apresentando desempenhos piores? Os professores utilizaram-se de critérios avaliativos sistêmicos com uns e não com outro? Ou a aprovação de alunos considerados fracos pelos docentes representa o reconhecimento do fracasso do ensino e a impotência dos docentes diante deste fenômeno? Enfim, são muitos os questionamentos e poucas as respostas encontradas. Daí a necessidade de se constituir tempos e espaços de formação docente para o enfrentamento de problemas, para que a escola consiga assumir seu papel de formadora do cidadão.

Os dados demonstram que o período de OER não representou avanços em termos de aprendizagem dos alunos, e os critérios para aprovação foram fundamentados não a partir das habilidades e competências adquiridas durante o ano, mas sob a ótica do que é permitido ou não no jogo do poder instituído. A avaliação tornou-se um instrumento leviano de poder, ao mesmo tempo em que possibilitou à escola se livrar de alunos indesejáveis, aprovando-os deliberadamente para outras escolas. Isto ilustra o caráter autoritário da avaliação, uma vez

\section{POLÊM!CA $\mid$ LABORE}

Polêmica - Revista Eletrônica da Uerj - Rua São Francisco Xavier, 524, $1^{\circ}$ andar bloco D, sl.1001 • Tels.: +55 21 2334-4088 / 4087 • http://www.e-publicacoes.uerj.br/index.php/polemica/index http://www.labore.uerj.br • laboreuerj@yahoo.com.br 
que a responsabilidade do professor é transferida ao aluno, como se este fosse o único capaz de alterar uma realidade previamente determinada. Tal fenômeno ameaça a própria noção de escola democrática, uma vez que a autoridade do adulto não é legitimada pela construção democrática, responsabilização e respeito mútuos, mas pelo exercício da violência institucional.

A presente pesquisa corroborou as discussões elencadas no referencial bibliográfico, demonstrando que a prática profissional ainda está calcada em vícios históricos e culturais que excluem os segmentos mais vulnerabilizados da sociedade. É preciso resgatar a autoridade professoral, na medida em que o professor consiga estabelecer com os alunos as regras, limites, pactos e reflexões sobre o clima escolar e seu impacto na aprendizagem. Educar não se resume a transmitir conteúdos, mas a prática ainda demonstra que os docentes continuam acreditando que condições ideais de ensino irão, necessariamente, conduzir à aprendizagem dos conteúdos. Esta desvinculação do sujeito com o objeto de conhecimento faz com que aspectos que não favorecem o ensino sejam encaminhados para outra instância, que não a sala de aula, delegando a outros a tarefa de educar em sua integralidade. Situações como esta denunciam a irracionalidade de um sistema excludente, classificador, opressor e individualista, e não traduzem, na prática, o discurso da universalização do ensino e do direito a uma educação pública de qualidade. Tal constatação sugere a importância de se qualificar o processo avaliativo, tanto no nível da formação do professor como na oferta de instrumentos que objetivem suas observações de modo confiável.

Também vale ressaltar o quanto os momentos de encontro da equipe de professores com a Coordenação Pedagógica são importantes para articular os procedimentos e justificar as condutas, evitando práticas individualistas e não fundamentadas pela equipe e para consolidar os conhecimentos teóricos que deveriam embasar a prática profissional.

A escola tem um compromisso social com seus alunos: educar tem de ser uma experiência prazerosa e uma oportunidade de vivenciar a democracia, a responsabilidade, a consciência e autonomia. Por isto, é preciso conhecer, reconhecer e enfrentar os desafios que se interpõem no processo educativo, de forma a promover o atendimento das novas demandas educacionais exigidas pela sociedade atual.

\section{POLÊM!CA $\mid$ LABORE}

Polêmica - Revista Eletrônica da Uerj - Rua São Francisco Xavier, 524, $1^{\circ}$ andar bloco D, sl.1001 • Tels.: +55 21 2334-4088/4087 • http://www.e-publicacoes.uerj.br/index.php/polemica/index http://www.labore.uerj.br • laboreuerj@yahoo.com.br 


\section{Referências}

ARROYO, Miguel G. Fracasso-sucesso: o peso da cultura escolar e do ordenamento da educação básica. Em aberto, Brasília, ano 11, n. 53, 1992.

. Fracasso/sucesso: um pesadelo que perturba nossos sonhos. Em aberto, Brasília, ano 17, n. 71, 2008.

BELO HORIZONTE. Prefeitura Municipal. Secretaria Municipal de Educação. Portaria 317 de 20 de novembro de 2014. Diário Oficial do Município. Belo Horizonte, MG, 22 nov. 2014.

BRASIL. Constituição (1988). Constituição da República Federativa do Brasil. Brasília: DF. Senado Federal: Centro Gráfico, 1988. Disponível em: http://www.planalto.gov.br/ccivil_03/Constituicao/Constituicao.htm. Acesso em: 30 set. 2018.

BRASIL. Lei No 9.394, de 20 de dezembro de 1996. Estabelece as diretrizes e bases da educação nacional. Diário Oficial da União, Brasília, DF, 23 dez. 1996. Disponível em:

<http://www.planalto.gov.br/ccivil_03/LEIS/L9394.htm>. Acesso em: 30 set. 2018.

CHARLOT, Bernard. A relação com o saber: conceitos e definições. In: Da relação com o saber: elementos para uma teoria. Tradução de Bruno Magne. Porto Alegre: Artes Médicas, 2000.

FREIRE, Paulo. Educação como prática da liberdade. Rio de Janeiro: Paz e Terra, 2015.

Pedagogia da Autonomia. Saberes Necessários à Prática Educativa. Rio de Janeiro: Paz e Terra, 1997.

JACOMINI, Márcia Aparecida. Por que a maioria dos pais e alunos defende a reprovação? Cadernos de Pesquisa, São Paulo, v. 40, n. 141, p. 895-919, 2010, Disponível em: <www.scielo.br/scielo.php?script=sci_arttext\&pid=S0100-15742010000300012\&lng=en\&nrm=iso>. Acesso em: 23 dez 2017. http://dx.doi.org/10.1590/S0100-15742010000300012.

LUCKESI, Cipriano Carlos. Avaliação da aprendizagem escolar: estudos e proposições. São Paulo: Cortez editora, 2014.

MORIN, Edgar. A cabeça bem feita. Rio de Janeiro: Bertrand Brasil, 2003.

Introdução ao pensamento complexo. Porto Alegre: Sulina, 2007.

ORTIZ, Renato. Pierre Bourdieu. São Paulo: Ática, 1983.

PACHANE, Graziela Giusti; DOMICIANO, Rodrigo Peres Lopes. Formação de professores das disciplinas específicas da educação básica: panorama das pesquisas sobre licenciaturas no Brasil pós-LDB. Série-EstudosPeriódico do Programa de Pós-Graduação em Educação da UCDB, n. 33, 2013.

PATTO, Maria Helena Souza. A Produção do Fracasso Escolar: histórias de submissão e rebeldia. São Paulo: Casa do Psicólogo, 1999.

PERRENOUD, Philippe. Dez novas competências para ensinar. Artmed editora, 2015.

PBH - PREFEITURA MUNICIPAL DE BELO HORIZONTE. Manual de Comunicações Administrativas. Belo Horizonte, 1984.

\section{POLÊM!CA $\mid$ LABORE}

Polêmica - Revista Eletrônica da Uerj - Rua São Francisco Xavier, 524, $1^{\circ}$ andar bloco D, sl.1001 • Tels.: +55 21 2334-4088 / 4087 • http://www.e-publicacoes.uerj.br/index.php/polemica/index http://www.labore.uerj.br • laboreuerj@yahoo.com.br 
Orientações sobre Processos de Avaliação no Ensino Fundamental da Rede Municipal de Educação de Belo Horizonte. Belo Horizonte, 2016.

RIBEIRO, Flávia. Edgar Morin, o Pensamento Complexo e a Educação. Pró-Discente: Caderno de Prod. Acad.Cient. Progr. Pós-Grad. Educ., Vitória-ES, v. 17, n. 2, jul./dez. 2011.

SAVIANI, Dermeval. Formação de professores: aspectos históricos e teóricos do problema no contexto brasileiro. Revista brasileira de educação, Campinas, 2009, p. 143-155.

SENICATO, Renato Bellotti; OMETTO, Cláudia Beatriz de Castro Nascimento. Discutindo sobre o fracasso escolar na perspectiva de Bernard Charlot: em foco uma escola pública paulista de educação básica. ETD Educação Temática Digital, Campinas, SP, v. 16, n. 2, p. 249-267, ago. 2014. ISSN 1676-2592. Disponível em: <https://periodicos.sbu.unicamp.br/ojs/index.php/etd/article/view/1318>. Acesso em: 23 dez. 2018.

Recebido em: 30/12/2017.

Aceito em: 30/09/2018.

\section{POLÊM!CA | LABORE}

Polêmica - Revista Eletrônica da Uerj - Rua São Francisco Xavier, 524, $1^{\circ}$ andar bloco D, sl.1001 • Tels.: +55 21 2334-4088 / 4087 • http://www.e-publicacoes.uerj.br/index.php/polemica/index http://www.labore.uerj.br • laboreuerj@yahoo.com.br 